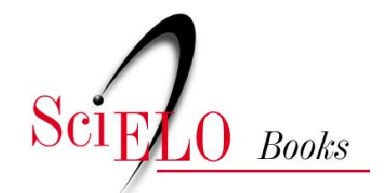

(40) Mackenzio

\title{
Capítulo 3
}

Contexto escolar: sistema de avaliação e competência em leitura

\section{Eva Cristina de Carvalho Souza Mendes \\ Decio Brunoni}

\section{SciELO Books / SciELO Livros / SciELO Libros}

MENDES, ECCS., and BRUNONI, D. Contexto escolar: sistema de avaliação e competência em leitura. In: Competência em leitura: interface entre contextos psicossocial, familiar e escolar [online]. São Paulo: Editora Mackenzie, 2015. Saberes em tese collection, vol. 11, pp. 45-73. ISBN: 978-858293-724-2. Available from: doi: 10.7476/9788582937242. Also available in ePUB from: http://books.scielo.org/id/g2v7w/epub/mendes-9788582937242.epub.

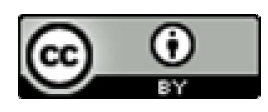

All the contents of this work, except where otherwise noted, is licensed under a Creative Commons Attribution $\underline{4.0 \text { International license. }}$

Todo o conteúdo deste trabalho, exceto quando houver ressalva, é publicado sob a licença Creative Commons Atribição 4.0.

Todo el contenido de esta obra, excepto donde se indique lo contrario, está bajo licencia de la licencia Creative Commons Reconocimento 4.0. 


\section{Contexto escolar: sistema de avaliação e competência em leitura}

\section{Contexto escolar}

O Ministério da Educação, por meio da Secretaria de Educação Básica, define como objetivos da Educação Infantil e do Ensino Fundamental:

[...] o desenvolvimento da capacidade de aprender, tendo como meios básicos o pleno domínio da leitura, da escrita e do cálculo [...], bem como [...] foco central na alfabetização, ao longo dos três primeiros anos [...] (BRASIL, 2013).

No que se refere à conquista da competência em leitura e escrita, o Ministério da Educação propõe que, além da inserção dos alunos em um ambiente com acesso aos diversos usos da leitura e da escrita, é necessário um trabalho sistemático, centrado tanto nos aspectos funcionais e textuais quanto no aprendizado dos aspectos gráficos da linguagem escrita e daqueles referentes ao sistema alfabético de representação (BRASIL, 2004). 
Assim, nessa perspectiva da avaliação da competência em leitura, será verificado o contexto escolar de um estudo realizado por Mendes (2014) em quatro escolas municipais que oferecem o Ensino Fundamental, em um município situado na região Sudeste, litoral do estado de São Paulo. As escolas estão localizadas nas zonas Leste, Central, Noroeste e em morros da cidade de Santos que a caracterizam como um todo.

As unidades municipais de educação (UME) de Santos que atendem o Ensino Fundamental estão enquadradas, segundo a escala de medição da infraestrutura escolar (NETO et al., 2013), no nível adequado, conforme dados obtidos na Secretaria Municipal de Educação de Santos. Nesse nível, as escolas têm em sua infraestrutura: água, sanitário, energia, esgoto, cozinha, sala de diretoria, sala de professores, biblioteca, laboratório de informática, quadra e/ou local que permite convívio social e desenvolvimento motor, equipamentos de TV, DVD, computadores, impressora, copiadora e acesso à internet.

Ainda de acordo com os pesquisadores, a escala de infraestrutura possibilita análises relevantes, visto que estudos demonstraram que as condições físicas e o ambiente escolar são variáveis que impactam a proficiência em todas as regiões brasileiras.

As escolas que participaram desse estudo enquadram-se no nível adequado, conforme dados obtidos em relatórios Censo/2013, no Departamento de Infraestrutura da Secretaria Municipal de Educação de Santos.

Participaram da pesquisa: 34 alunos da Zona Leste, 42 da Zona Central, 32 da Zona Noroeste e 34 da Zona Morros.

\section{Sistema de avaliação no desempenho de leitura e escrita}

A qualidade do ensino tem sido motivo de preocupação nas esferas municipal, estadual e federal. Por essa razão, o governo brasileiro instituiu avaliações oficiais, padronizadas e em larga escala com o objetivo de acompanhar o rendimento dos alunos matriculados nas 
redes oficiais de ensino. Desde a década de 1990, o desenvolvimento das avaliações em grande escala tem se voltado a subsidiar a elaboração de diagnósticos sobre a realidade educacional e a orientação para formular políticas públicas visando à promoção da equidade e da melhoria do ensino brasileiro (SOUSA; ARCAS, 2010). É fundamental que as avaliações em grande escala de fato contribuam para a melhoria do processo de ensino e aprendizagem, de modo que os brasileiros, sejam crianças, adolescentes ou adultos, adquiram as habilidades e competências necessárias à leitura e escrita.

Ocorre que, mesmo com os avanços recentemente divulgados pelo MEC por meio do Ideb, os indicadores em Língua Portuguesa apurados pela média total na Prova Brasil 2011, nos anos iniciais do Ensino Fundamental, refletem 190,6 de um total de 350 pontos. Esse resultado está enquadrado no nível 3 de desempenho em leitura, conforme a escala de desempenho de Língua Portuguesa Ensino Fundamental, que vai até o nível 9 (BRASIL, 2011).

Para apurar detalhadamente a Educação Básica, a Prova Brasil foi regulamentada em 2005, por meio da Portaria Inep nº 69. As escolas públicas localizadas na zona urbana devem se submeter a essa prova, cujo objetivo é avaliar a qualidade do ensino ministrado nesses locais. A aplicação ocorre para alunos de $5^{\circ}$ e $9^{\circ}$ anos do Ensino Fundamental, anteriormente denominados $4^{\underline{a}}$ e $8^{\underline{a}}$ séries. Os testes aos quais os alunos são submetidos são de Língua Portuguesa e Matemática.

Os resultados da Prova Brasil são apresentados em uma escala de desempenho por disciplina. A escala de Língua Portuguesa é composta por nove níveis: 125, 150 e assim sucessivamente até o nível 9, com um total de 350 pontos. Os níveis são constituídos por habilidades individuais acrescidas às dos níveis anteriores.

O Quadro 1 descreve os níveis da escala de desempenho de Língua Portuguesa da Prova Brasil.

No estado de São Paulo, os resultados da Prova Brasil 2011 Língua Portuguesa apontam como média total (rede pública e privada) 
QUADRO 1 •ESCALA DE DESEMPENHO DE LÍNGUA PORTUGUESA DA PROVA BRASIL

\begin{tabular}{|c|c|}
\hline $\begin{array}{c}\text { NÍVEIS DE } \\
\text { DESEMPENHO } \\
\text { DOS ALUNOS } \\
\text { EM LEITURA }\end{array}$ & 0 QUE OS ALUNOS CONSEGUEM FAZER NESSE NÍVEL \\
\hline $\begin{array}{l}\text { NÍVEL } 0 \text { - } \\
\text { ABAIXO } \\
\text { DE } 125\end{array}$ & $\begin{array}{l}\text { A Prova Brasil não utilizou itens que avaliam as habilidades abaixo deste nível. } \\
\text { Os alunos localizados abaixo do nível } 125 \text { requerem atenção especial, pois } \\
\text { não demonstram habilidades muito elementares, como as de: } \\
\text { - localizar informação (exemplo: o personagem principal, local e tempo } \\
\text { da narrativa); } \\
\text { - identificar o efeito de sentido decorrente da utilização de recursos } \\
\text { gráficos (exemplo: letras maiúsculas chamando a atenção em um cartaz); } \\
\text { - identificar o tema, em um texto simples e curto. }\end{array}$ \\
\hline $\begin{array}{l}\text { NÍVEL } 1 \text { - } \\
125 \text { A } 150\end{array}$ & $\begin{array}{l}\text { Os alunos de } 5^{0} \text { e } 9^{0} \text { anos ( } 4^{a} \text { e } 8^{a} \text { séries): } \\
\text { - } \quad \text { localizam informações explícitas em textos narrativos curtos, } \\
\text { informativos e anúncios; } \\
\text { - } \quad \text { identificam o tema de um texto; } \\
\text { - } \quad \text { localizam elementos como o personagem principal; } \\
\text { - } \quad \text { estabelecem relação entre partes do texto: personagem e ação; ação } \\
\text { e tempo; ação e lugar. }\end{array}$ \\
\hline $\begin{array}{l}\text { NÍVEL } 2 \text { - } \\
150 \text { A } 175\end{array}$ & 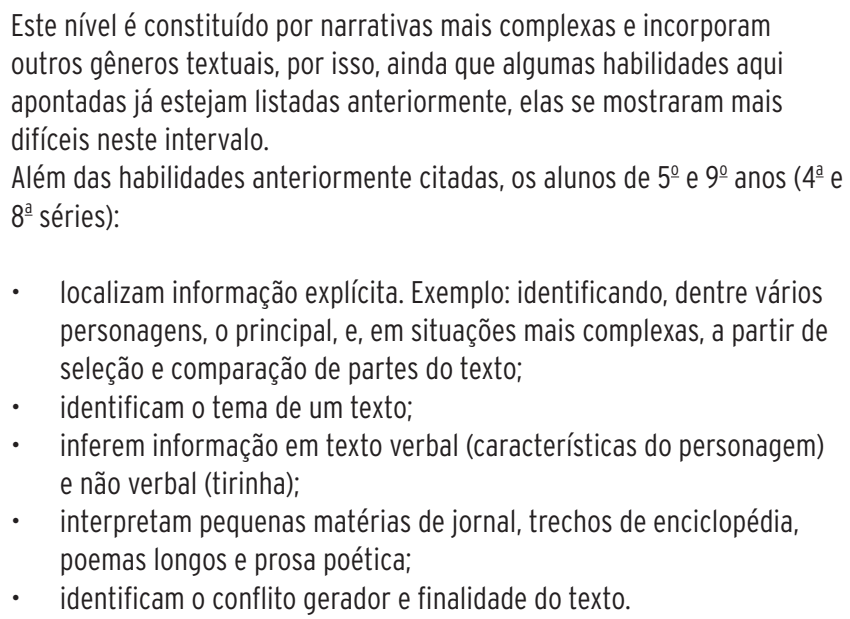 \\
\hline $\begin{array}{l}\text { NÍVEL } 3 \text { - } \\
175 \text { A } 200\end{array}$ & $\begin{array}{l}\text { Além das habilidades anteriormente citadas, os alunos de } 5^{0} \text { e } 9^{0} \text { anos ( } 4^{a} \text { e } \\
8^{a} \text { séries): } \\
\text { - interpretam, a partir de inferência, texto não verbal (tirinha) de maior } \\
\text { complexidade temática; }\end{array}$ \\
\hline
\end{tabular}


QUADRO 1 • ESCALA DE DESEMPENHO DE LÍNGUA PORTUGUESA DA PROVA BRASIL (CONTINUAÇÃO)

\begin{tabular}{|c|c|}
\hline $\begin{array}{l}\text { NÍVEIS DE } \\
\text { DESEMPENHO } \\
\text { DOS ALUNOS } \\
\text { EM LEITURA }\end{array}$ & O QUE OS ALUNOS CONSEGUEM FAZER NESSE NÍVEL \\
\hline $\begin{array}{l}\text { NÍVEL } 3 \text { - } \\
175 \text { A } 200\end{array}$ & $\begin{array}{l}\text { - identificam o tema a partir de características que tratam de } \\
\text { - } \quad \text { rentimentos do personagem principal; } \\
\text { vocabulário complexos. }\end{array}$ \\
\hline $\begin{array}{l}\text { NÍVEL } 4 \text { - } \\
200 \text { A } 225\end{array}$ & 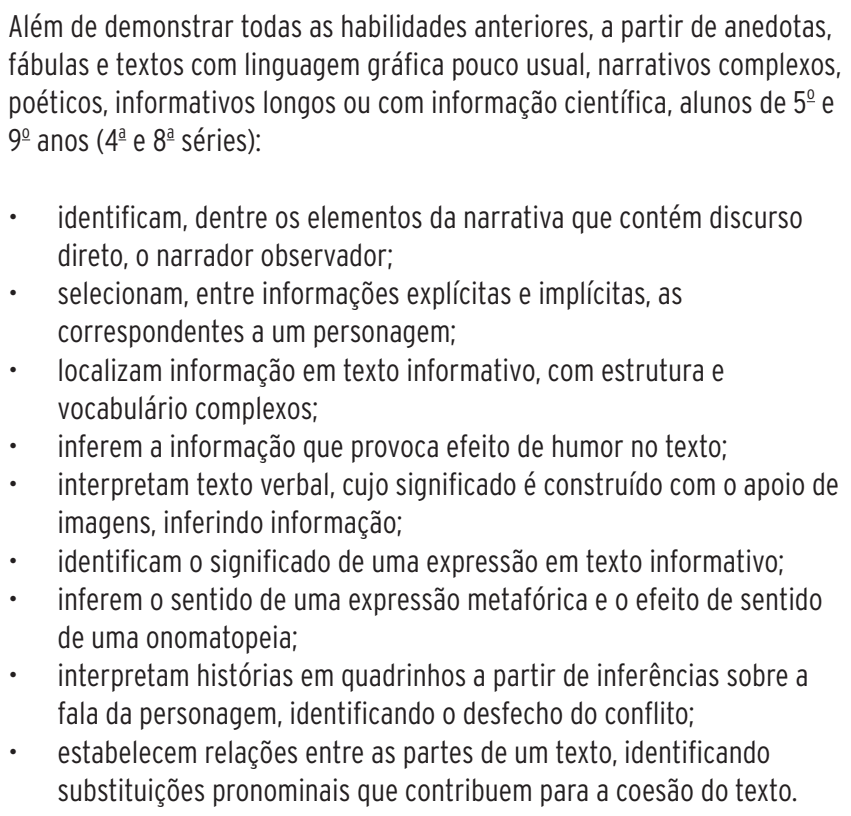 \\
\hline $\begin{array}{l}\text { NÍVEL } 5 \text { - } \\
225 \text { A } 250\end{array}$ & 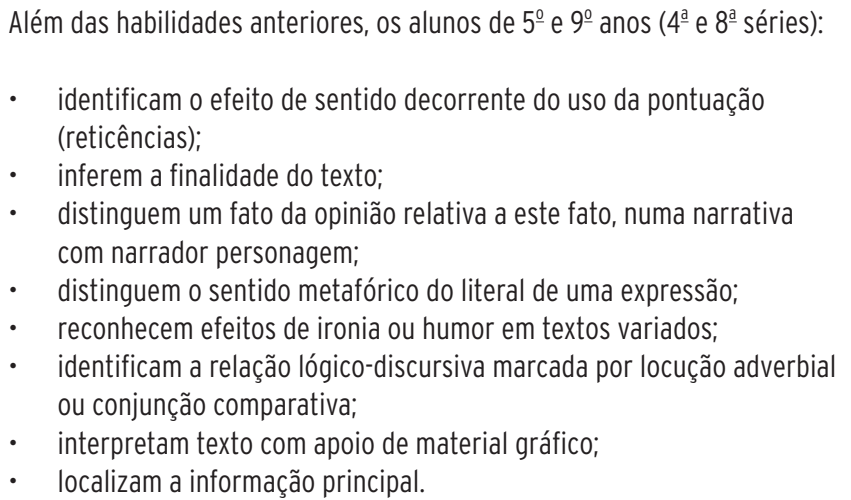 \\
\hline
\end{tabular}


QUADRO 1 • ESCALA DE DESEMPENHO DE LÍNGUA PORTUGUESA DA PROVA BRASIL (CONTINUAÇÃO)

\begin{tabular}{|c|c|}
\hline $\begin{array}{l}\text { NÍVEIS DE } \\
\text { DESEMPENHO } \\
\text { DOS ALUNOS } \\
\text { EM LEITURA }\end{array}$ & 0 QUE OS ALUNOS CONSEGUEM FAZER NESSE NÍVEL \\
\hline $\begin{array}{l}\text { NÍVEL } 5 \text { - } \\
225 \text { A } 250\end{array}$ & $\begin{array}{l}\text { Os alunos de } 9^{0} \text { ano ( } 8^{a} \text { série), neste nível, ainda: } \\
\text { - } \quad \text { inferem o sentido de uma palavra ou expressão; } \\
\text { - estabelecem relação causa/consequência entre partes e elementos } \\
\text { do texto; } \\
\text { - } \quad \text { identificam o tema de textos narrativos, argumentativos e poéticos de } \\
\text { conteúdo complexo; } \\
\text { - identificam a tese e os argumentos que a defendem em textos } \\
\text { argumentativos; } \\
\text { - reconhecem o efeito de sentido decorrente da escolha de uma } \\
\text { determinada palavra ou expressão. }\end{array}$ \\
\hline $\begin{array}{l}\text { NÍVEL } 6 \text { - } \\
250 \text { A } 275\end{array}$ & 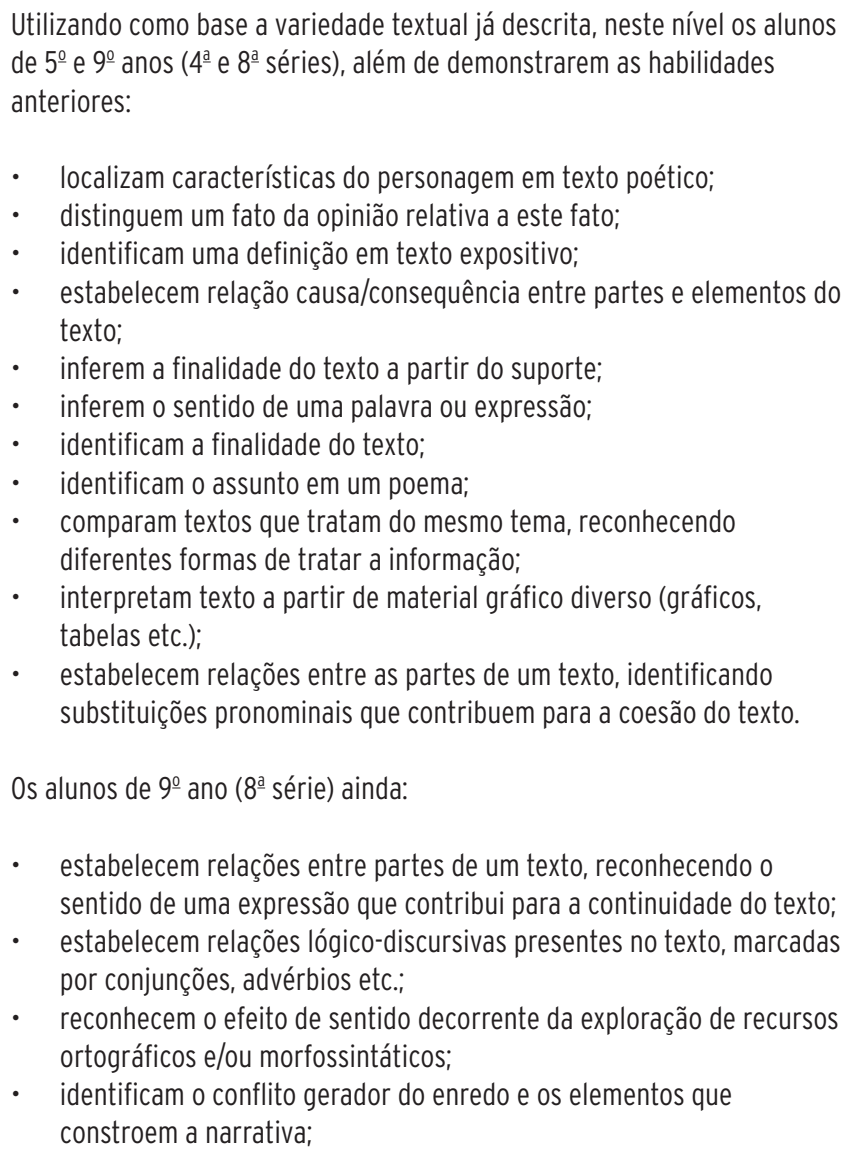 \\
\hline
\end{tabular}


QUADRO 1 • ESCALA DE DESEMPENHO DE LÍNGUA PORTUGUESA DA PROVA BRASIL (CONTINUAÇÃO)

\begin{tabular}{|c|c|}
\hline $\begin{array}{c}\text { NÍVEIS DE } \\
\text { DESEMPENHO } \\
\text { DOS ALUNOS } \\
\text { EM LEITURA }\end{array}$ & 0 QUE OS ALUNOS CONSEGUEM FAZER NESSE NÍVEL \\
\hline $\begin{array}{l}\text { NÍVEL } 6 \text { - } \\
250 \text { A } 275\end{array}$ & $\begin{array}{l}\text { - identificam a tese e o argumento que defendem em texto com a } \\
\text { linguagem informal; } \\
\text { - inferem informação a partir de um julgamento em textos narrativos } \\
\text { longos; } \\
\text { - inferem efeitos de ironia ou humor em narrativas curtas; } \\
\text { - inferem o sentido de uma expressão em texto narrativo longo e de } \\
\text { vocabulário complexo. }\end{array}$ \\
\hline $\begin{array}{l}\text { NÍVEL } 7 \text { - } \\
275 \text { A } 300\end{array}$ & 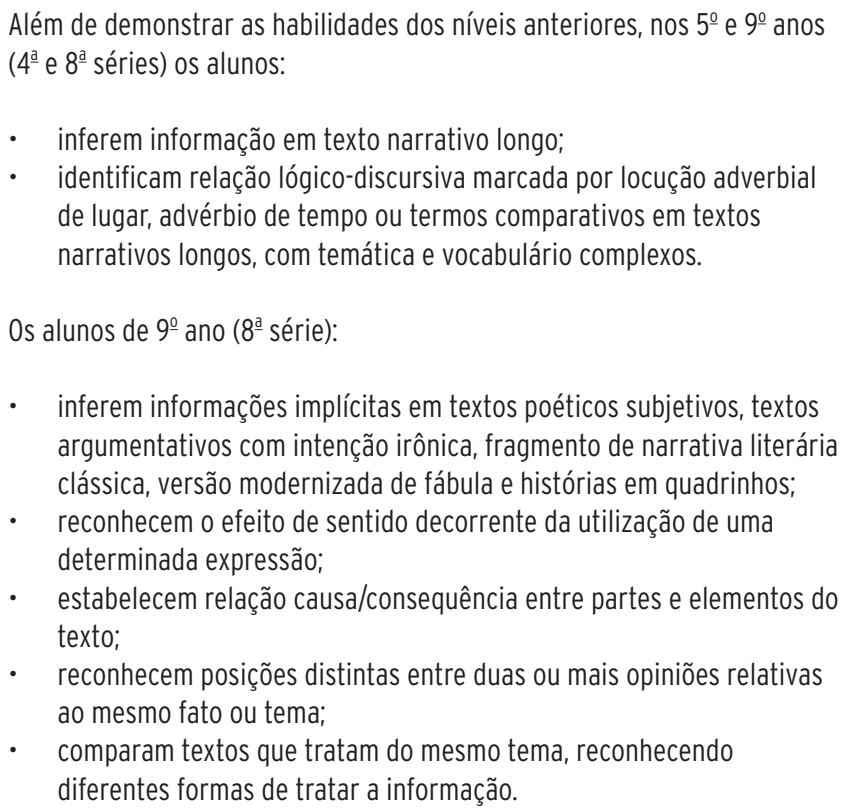 \\
\hline $\begin{array}{l}\text { NÍVEL } 8 \text { - } \\
300 \text { A } 325\end{array}$ & $\begin{array}{l}\text { Além de demonstrar as habilidades dos níveis anteriores, nos } 5^{0} \text { e } 9^{0} \text { anos } \\
\text { (4a e } 8^{a} \text { séries) os alunos: } \\
\text { - identificam o assunto do texto em narrativas longas com vocabulário } \\
\text { complexo; } \\
\text { - inferem informações em fábulas. } \\
\text { Os alunos de } 9^{\circ} \text { ano ( } 8^{a} \text { série): } \\
\text { - inferem o tema de texto poético; } \\
\text { - inferem a finalidade de texto informativo; } \\
\text { - identificam a opinião do autor em texto informativo com vocabulário } \\
\text { complexo; }\end{array}$ \\
\hline
\end{tabular}


QUADRO 1 • ESCALA DE DESEMPENHO DE LÍNGUA PORTUGUESA DA PROVA BRASIL (CONTINUAÇÃO)

\begin{tabular}{|c|c|}
\hline $\begin{array}{l}\text { NÍVEIS DE } \\
\text { DESEMPENHO } \\
\text { DOS ALUNOS } \\
\text { EM LEITURA }\end{array}$ & O QUE OS ALUNOS CONSEGUEM FAZER NESSE NÍVEL \\
\hline $\begin{array}{l}\text { NÍVEL } 8 \text { - } \\
300 \text { A } 325\end{array}$ & $\begin{array}{l}\text { - } \quad \text { diferenciam as partes principais das secundárias de um texto; } \\
\text { - } \quad \text { interpretam tabela a partir da comparação entre informações; } \\
\text { - } \quad \text { estabelecem relação entre a tese e os argumentos oferecidos para } \\
\text { - } \quad \text { idententá-la; } \\
\text { - } \quad \text { identificam a tese de um texto argumentativo; } \\
\text { - } \quad \text { reconflito gerador do enredo; } \\
\text { outras notações. }\end{array}$ \\
\hline $\begin{array}{l}\text { NÍVEL } 9 \text { - } \\
325 \text { A } 350\end{array}$ & $\begin{array}{l}\text { Além das habilidades descritas anteriormente, os alunos de } 9^{0} \text { ano ( } 8^{\mathrm{a}} \\
\text { série) localizados neste nível demonstram habilidades de leitura que } \\
\text { envolvem: compreensão global de texto e avaliação e estabelecimento de } \\
\text { relações entre textos e partes de textos mais longos e com vocabulário } \\
\text { complexos. Além disso, inferem informações em diversos contextos e } \\
\text { começam a ler com compreensão textos da literatura clássica. }\end{array}$ \\
\hline
\end{tabular}

FONTE: BRASIL (2011).

200,0 pontos, o que equivale ao nível 3 na escala de desempenho. Nesse nível, o aluno tem habilidade para localizar informações explícitas em textos narrativos curtos, identificar o tema do texto, inferir informação em texto verbal e não verbal, interpretar pequenas matérias de jornal, reconhecer elementos que compõem uma narrativa com temática e vocabulários complexos (BRASIL, 2011).

Para o município de Santos, os resultados apontaram 201,7 pontos, o que equivale à pontuação inicial correspondente ao nível 4. Nesse nível, o aluno tem habilidade para localizar informações explícitas em textos narrativos curtos, identificar o tema do texto, inferir informação em texto verbal e não verbal, interpretar pequenas matérias de jornal e reconhecer elementos que compõem uma narrativa com temática e vocabulários complexos. A criança também é capaz de interpretar histórias em quadrinhos a partir de inferências sobre a fala da personagem e estabelecer relações entre as partes de um texto, conforme a escala de desempenho de Língua Portuguesa no Ensino Fundamental (BRASIL, 2011). 
Nos resultados do Programa Internacional de Avaliação de Alunos (Pisa) 2009, o Brasil, em que pese a melhoria de desempenho apresentada, aparece na $55^{\underline{a}}$ posição, abaixo da média, principalmente no que tange às competências leitoras, segundo dados do Inep. Trata-se de um programa internacional de avaliação comparada, aplicado a partir da $7^{\underline{a}}$ série do Ensino Fundamental (atualmente $8^{\circ}$ ano), cujo objetivo é produzir indicadores da qualidade da educação ministrada nos países participantes, avaliando as competências dos estudantes em leitura, matemática e ciências.

Oliveira (2005) aponta que 55\% dos alunos brasileiros com 13 anos de idade, matriculados nas $7^{\underline{a}}$ e $8^{\underline{a}}$ séries do Ensino Fundamental (atualmente $8^{\circ}$ e $9^{\circ}$ anos) apresentam nível mais básico de leitura: o da identificação das palavras.

De acordo com os resultados do Saresp 2011, cerca de 71\% das escolas da rede estadual apresentaram, na avaliação dos alunos de $3^{\circ}$ ano do Ensino Fundamental, bom desempenho para leitura, conforme critério do teste, qual seja, 53,5 de um total de 72 pontos. Já na avaliação dos alunos de $5^{\circ}$ ano do Ensino Fundamental, a média foi de 195 pontos em Língua Portuguesa. Esse resultado equivale ao nível básico de proficiência e domínio mínimo dos conteúdos, das competências e das habilidades necessárias para interagir com a proposta curricular do ano subsequente.

Capellini, Tonelotto e Ciasca (2004) apontam que uma avaliação formal, inicial e referencial realizada pelo professor é um critério útil para investigação do desempenho das crianças, pois fornece elementos para verificar a coerência entre o julgamento dos professores (em avaliações não padronizadas) e os resultados de testes padronizados. Estes podem apresentar vantagens, conforme indicado por Nikaedo, Kuriyama e Macedo (2007, p. 192):

[...] os resultados não estão tão sujeitos ao julgamento subjetivo de cada professor; possibilitam caracterizar melhor o padrão de leitura 
e escrita de cada estudante; permitem a elaboração de estratégias específicas de intervenção em função das dificuldades apresentadas pelos alunos; possibilitam o estabelecimento de medidas objetivas de comparação entre escolas com metodologias e orientações pedagógicas diferentes e permitem o acompanhamento mais preciso do desenvolvimento do escolar ao longo do ano.

Em meio às iniciativas de avaliação para indicar a melhoria na qualidade de ensino e aprendizagem das crianças brasileiras, o MEC institui a Provinha Brasil, pela Portaria Normativa $\mathrm{n}^{\mathrm{o}}$ 10/2007 (BRASIL, 2007). O objetivo é diagnosticar as habilidades de leitura e letramento/alfabetização de crianças das redes públicas de Ensino Fundamental, a fim de possibilitar ações e intervenções mais efetivas na alfabetização dos alunos dos anos iniciais dessa etapa.

\section{A Provinha Brasil - Leitura}

A Provinha Brasil é um instrumento avaliativo, instituído pelo MEC em 2007, e tem a finalidade de identificar o nível de alfabetização das crianças matriculadas no $2^{\circ}$ ano do Ensino Fundamental da rede pública e diagnosticar insuficiências na leitura e na escrita.

Nessa avaliação, de acordo com as instruções do MEC, a adesão é voluntária e aberta a todas as escolas do país, com a finalidade de permitir intervenções corretoras, caso sejam diagnosticadas insuficiências em leitura e escrita dos alunos avaliados.

As avaliações em larga escala instituídas pelo MEC são construídas a partir de uma matriz de referência, isto é, documentos que orientam seu conteúdo e a elaboração das questões que a compõem (GONTIJO, 2012).

As habilidades de leitura e escrita constituintes da Provinha Brasil tiveram sua base veiculada em duas matrizes de referência: 
a primeira vigorou no ano de 2008, quando houve a aplicação do primeiro teste, e a segunda, a partir de 2009. A primeira continha três eixos: 1 . apropriação do sistema de escrita: habilidades relacionadas à identificação e ao reconhecimento de princípios do sistema de escrita; 2. leitura; 3. escrita. A matriz de referência sofreu alteração no ano de 2009, e o eixo escrita, essencial no processo de alfabetização, foi retirado do documento (GONTIJO, 2012).

As habilidades que constam na matriz de referência estão fundamentadas na concepção de que alfabetização e letramento são processos que devem ser desenvolvidos de maneira complementar e paralela. Consideram a alfabetização como o desenvolvimento da compreensão das regras de funcionamento do sistema de escrita alfabética e o letramento como as possibilidades de usos e funções sociais da linguagem escrita, isto é, como processo de inserção e participação dos sujeitos na cultura escrita (BRASIL, 2009).

A matriz de referência vigente para avaliar a alfabetização e o letramento inicial da Provinha Brasil é composta por um conjunto de 10 descritores (habilidades), distribuídos em dois eixos:

Eixo 1 - Apropriação do sistema de escrita: habilidades relacionadas à identificação e ao reconhecimento de princípios do sistema de escrita. Nesse eixo, há três descritores:

» D1: Reconhecer letras. O aluno deverá diferenciar letras de outros signos gráficos, identificar pelo menos as letras do alfabeto ou reconhecer os diferentes tipos de grafia das letras.

» D2: Reconhecer sílabas. Nesse descritor, o aluno deverá identificar o número de sílabas que formam uma palavra por contagem ou comparação das sílabas de palavras dadas por imagem.

» D3: Estabelecer relação entre unidades sonoras e suas representações gráficas. O aluno deverá identificar a representação de unidades sonoras, como letras que possuem correspon- 
dência sonora única $(p, b, t, d, f)$, letras com mais de uma correspondência sonora $(c$ e $g)$ e sílabas.

Eixo 2 - Leitura. Nesse eixo, estão contidos sete descritores:

» D4: Ler palavras. Nesse descritor a criança deverá identificar a escrita de uma palavra ditada ou ilustrada, sem que isso seja possível a partir do reconhecimento de um único fonema ou de uma única sílaba.

» D5: Ler frases. A criança deverá localizar informações em enunciados curtos e de sentido completo, sem que isso seja possível a partir das estratégias de identificação de uma única palavra que liga o gabarito à frase.

» D6: Localizar informação explícita em textos. Nesse quesito, a criança deverá localizar informação em diferentes gêneros textuais, com diferentes tamanhos, estruturas e graus de evidência da informação, o que exige, em alguns casos, que relacione dados do texto para chegar à resposta correta.

» D7: Reconhecer o assunto de um texto. Trata-se de antecipar o assunto do texto com base no suporte, nas características gráficas do gênero ou, em um nível mais complexo, reconhecer o assunto com base apenas na leitura individual do texto.

» D8: Identificar finalidades do texto. A criança deverá antecipar a finalidade do texto com base no suporte, nas características gráficas do gênero ou, em um nível mais complexo, identificar a finalidade, apoiando-se apenas na leitura individual do texto.

» D9: Estabelecer relação entre as partes do texto. A criança, nesse descritor, deverá identificar repetições e substituições que contribuem para a coerência e a coesão textuais.

» D10: Inferir informação (BRASIL, 2009).

Desde 2011, o instrumental da Provinha Brasil é constituído de um kit composto por: 
1 Caderno de teste do aluno com as questões que serão respondidas.

2 Guia de aplicação: caderno com os procedimentos de aplicação e as questões a serem aplicadas aos alunos.

3 Guia de correção e interpretação de resultados: caderno com as principais informações sobre a Provinha Brasil - seus objetivos, pressupostos teóricos e metodologia -, orientações para a correção do teste, possibilidades de interpretação e uso dos seus resultados.

4 Reflexões sobre a prática.

Desde 2011, o instrumento é composto por 20 questões de múltipla escolha, com quatro opções de resposta para cada uma. $\mathrm{O}$ avaliador propicia na aplicação três tipos de comando: totalmente lidas pelo aplicador, parcialmente lidas pelo aplicador e lidas pelo aluno individualmente. Seguindo esses comandos, é necessário verificar se a audição e a visão do avaliado estão preservadas.

O critério definido para identificar os níveis de desempenho dos alunos é obtido pelo número de acertos verificados (BRASIL, 2012d). São cinco níveis e para cada um deles foi descrito um conjunto de habilidades:

» Nível 1 - até 3 acertos: o aluno encontra-se em um estágio inicial do processo de alfabetização. Isso significa que está no início da apropriação das habilidades referentes ao domínio das regras que orientam o uso do sistema alfabético para leitura e escrita - identifica valor sonoro das partes iniciais ou finais da palavra, reconhece algumas letras do alfabeto e inicia a distinção entre letra, desenhos e outros sinais gráficos.

» Nível 2 - de 4 a 8 acertos: o aluno associa adequadamente letras e sons, estabelece relação entre grafemas e fonemas, lê palavras compostas por sílabas canônicas $(\mathrm{CV})$, lê algumas palavras compostas por sílabas não canônicas (CVC/ 
CCV) e reconhece palavras de formação silábica canônica escritas de diferentes formas.

» Nível 3 - de 9 a 13 acertos: o aluno é capaz de ler palavras de diferentes tamanhos e padrões silábicos, ler frases com sintaxe simples (sujeito + verbo + objeto) e localizar informações em uma frase ou em um texto de aproximadamente cinco linhas.

» Nível 4 - de 14 a 18 acertos: o aluno lê textos de aproximadamente oito a 10 linhas, na ordem direta, de estrutura sintática simples e de vocabulário adequado ao repertório explorado na escola, e tece inferências simples.

» Nível 5 - de 19 a 20 acertos: além de ter as habilidades dos outros quatro níveis, o aluno é capaz de compreender textos de diferentes gêneros e de complexidade diversa, identificando o assunto principal, localizando informações não evidentes e fazendo inferências.

Cabe salientar que cada um desses níveis engloba as habilidades anteriores e acrescenta novas, indicando em que ponto do processo de alfabetização os alunos se encontram.

A possibilidade de comparação entre as avaliações externas, como é o caso da Provinha Brasil - que não é um instrumento psicométrico, mas sim um instrumento padronizado e pautado em parâmetros normativos -, e a avaliação da aprendizagem realizada na prática cotidiana do professor é uma ferramenta importante para a sugestão de estratégias pedagógicas e de avaliação.

Da mesma maneira, a comparação entre avaliações oficiais, como é o caso da Provinha Brasil, e dos Parâmetros Curriculares Nacionais (PCN) pode contribuir para o entendimento das competências requeridas no desenvolvimento da leitura e da escrita, além de constatar se as propostas de verificação do rendimento escolar, tanto nas avaliações quanto nos parâmetros, estão em acordo. 
Os resultados da Provinha Brasil, que servem para apontar um diagnóstico individual do alunado, permitem calcular médias que expressem o percentual de acertos de cada uma das turmas e verificar a média obtida pelas escolas participantes.

Em Santos, a Provinha Brasil passou a ser aplicada já em sua primeira versão, em 2008. No ano de 2011, os resultados indicaram que das 36 UMEs a maior parte $(82,9 \%)$ obteve entre 16 e 18 acertos nas questões, o que corresponde ao nível 4, e 8,33\% obtiveram entre 13 e 15 acertos.

Os resultados obtidos em 2012 pelas 36 UMEs avaliadas indicaram que $83 \%$ dos alunos estavam no nível 4 , enquanto $4 \%$ encontravam-se no nível 3, e os demais, distribuídos entre os níveis 2 e 5, conforme o Quadro 1.

O Gráfico 1 apresenta as médias dos resultados obtidos pelas 36 UMEs nos anos de 2011 e 2012 na Provinha Brasil - Leitura 2. Em 2011, a média foi de 16,5 pontos e, em 2012, de 17 pontos, ou seja, as médias desses anos apontam nível médio 4.

GRÁFICO 1 • MÉDIA DOS RESULTADOS OBTIDOS EM 36 UMES NOS ANOS DE 2011 E 2012

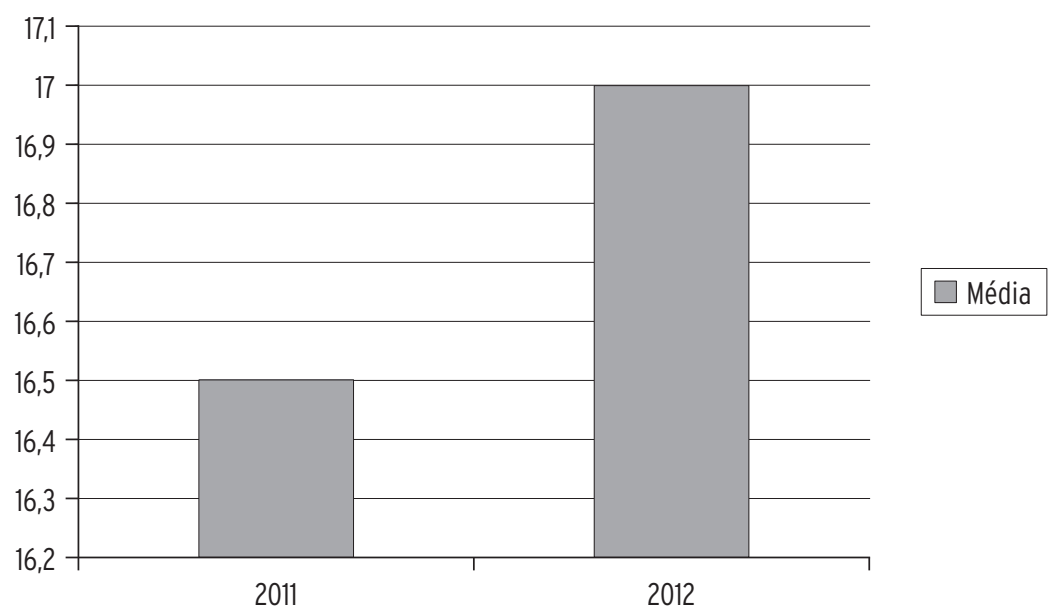

Média dos resultados obtidos na Provinha Brasil - Leitura 2: $2011=16,5 ; 2012=17$. Pontuação total: 20 pontos. 
A Provinha Brasil - Leitura 2012 - teste 2 é composta por: uma questão-exemplo, para orientar os alunos sobre como responder ao teste, e 20 questões de múltipla escolha, com quatro alternativas em cada uma. Há três tipos de enunciado nas questões:

1 totalmente lidas pelo professor/aplicador, com questões cujos enunciados e alternativas precisam ser completamente lidos pelo aplicador;

2 parcialmente lidas pelo professor/aplicador, em que serão lidos os todos os enunciados ou somente um deles. Pode também ser lido o texto para que os alunos acompanhem;

3 lidas pelos alunos individualmente. $\mathrm{O}$ aplicador deverá apenas explicar aos alunos que eles farão a leitura do texto, dos enunciados e das alternativas sozinhos. A pontuação total para esse teste é 20 pontos.

Para melhor entendimento da Provinha Brasil - Leitura 2012 - teste 2, Mendes (2013) analisa a matriz curricular da referida prova à luz da abordagem cognitiva de leitura, na qual se detecta que o primeiro bloco de questões - composto das questões 1 a 11 - tem como enfoque o desenvolvimento das habilidades de codificação e decodificação. Já o segundo bloco é composto de nove questões que envolvem a compreensão leitora a partir do conteúdo global do discurso e da retenção da informação textual. Como pode ser verificado, há oito questões do Eixo 1 que enfatizam as habilidades fonológicas, enquanto as questões de 9 a 20 são destinadas a avaliar a compreensão leitora, que requer o reconhecimento de letras, a representação fonológica da palavra, mas também o significado mais apropriado ao contexto, integrando-o ao sentido do texto para permitir que sejam tecidas inferências pautadas em seu conhecimento de mundo. Na prova, também não há questões que envolvam a leitura de pseudopalavras, reconhecida- 
mente a forma mais adequada para avaliar competências de decodificação. Em sua maioria são apresentadas palavras simples no estilo (CV, VC, CVCC), que têm regularidade e, em geral, compõem o repertório vocabular do aluno no nível de escolaridade referido para a aplicação do teste, isto é, o $2^{\underline{0}}$ ano do Ensino Fundamental. Essa avaliação não envolve leitura em voz alta, apenas silenciosa, e também não trata das questões pertinentes à escrita. Em suma, pode-se verificar que metade da Provinha Brasil enfoca as habilidades necessárias para a aquisição da competência em leitura e escrita apontadas pelo modelo teórico de leitura da abordagem cognitiva, e apenas $45 \%$ da prova trata das habilidades necessárias ao letramento.

Para a explicitação das questões, foi feita uma análise das competências e habilidades avaliadas na Provinha Brasil - Leitura sob a ótica da abordagem cognitiva de leitura, da seguinte maneira:

Nas questões de 1 a 8 , são solicitadas a identificação de grafema/fonema, letra inicial da palavra, primeira sílaba, mesma sílaba da palavra indicada por meio da imagem e do som, leitura de palavra a partir de imagem e identificação do número de sílabas, que poderá ser feita pela rota fonológica. Exemplos:

\section{Questão 1}

Observe a figura:

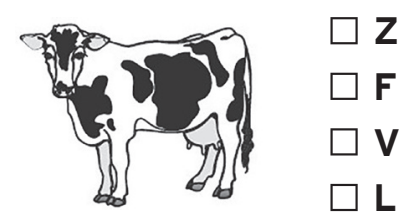

A letra V faz parte da escrita da palavra VACA. Marque um $\mathrm{X}$ no quadradinho em que aparece a letra $\mathrm{V}$. 


\section{Questão 8}

Conte o número de sílabas que tem no nome do objeto e depois marque o quadradinho que representa esse número.

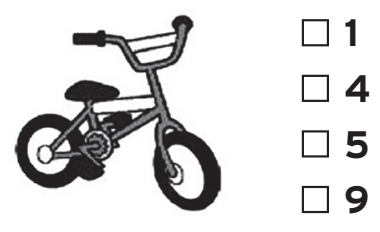

$\mathrm{Na}$ questão 9, de compreensão textual, a partir da leitura silenciosa do texto, que contém palavras e imagem, e da indicação do que o avaliador precisa fazer, o avaliado deve indicar qual das alternativas apresenta o item a ser doado.

No item 10, para a compreensão de leitura, é necessário estabelecer a correspondência entre a imagem e a leitura das frases contidas nas alternativas. Essa questão envolve o processo sintático e a estrutura gramatical de processamento sintático.

$\mathrm{Na}$ questão 11, a partir da leitura silenciosa das palavras contidas nas alternativas, o avaliado deve estabelecer a relação entre o par figura-escrita composta de palavras regulares e irregulares ortograficamente.

No item 12, é preciso atenção, pois o aplicador lê um texto enquanto a criança acompanha com a leitura silenciosa. Em seguida, o avaliado, a partir da compreensão textual, deve identificar o assunto do texto.

No quesito 13, o avaliado precisa inferir, a partir da leitura, a finalidade do texto, ou seja, por meio de habilidades metalinguísticas de nível fonológico, morfológico e sintático, deve atingir a habilidade cognitiva de inferência.

$\mathrm{Na}$ questão 14, solicita-se a compreensão textual. Nesse caso, o avaliado acompanha silenciosamente a leitura oral do texto, que contém palavras e imagem, feita pelo avaliador. Em seguida, o avaliador deve solicitar que o avaliado identifique a persona- 
gem principal do texto, o que exige memória, extração de significado pelo conteúdo semântico local (microestrutura) para chegar ao conteúdo semântico global (macroestrutura) que abarca as ideias essenciais do texto.

O item 15 exige compreensão textual do avaliado, que, a partir da leitura silenciosa do texto, deverá inferir informações sobre o texto por meio de suas micro e macroestruturas.

Nas questões 16 e 17, o avaliado deverá inferir, a partir da leitura, a finalidade do texto e compreendê-lo pelas suas características formais e também pelos conhecimentos prévios.

Nos quesitos de 18 a 20, a partir de leitura silenciosa realizada pelo avaliado ou da leitura oral feita pelo avaliador, o avaliado deve chegar à compreensão do texto pelas suas características formais e pelos conhecimentos prévios micro e macroestruturais do texto.

\section{Testes para medição das competências em leitura em um contexto escolar}

No Brasil, existem diversos testes para medição das competências em leitura: Capovilla e Capovilla (2006), Seabra e Capovilla (2010), Cuetos, Rodrigues e Rueno (2010), entre outros.

Para elucidar os testes de competência em leitura e escrita, serão apresentados os testes de avalição utilizados no contexto escolar por Mendes (2014). Foram selecionadas, por meio de amostragem aleatória, utilizando a divisão das escolas por zoneamento para a região insular da Secretaria Municipal de Educação de Santos, quatro UMEs do município de Santos sorteadas entre as 33 escolas que abrangem quatro áreas geográficas: Leste, Central, Noroeste e Morros, sendo uma para cada área.

Teste de Competência de Leitura de Palavras e Pseudopalavras (TCLPP) (SEABRA; CAPOVILLA, 2010), cujo objetivo é avaliar 
a competência de leitura silenciosa de palavras isoladas. É constituído de oito itens de treino e 70 itens de teste, e cada item é composto por um par que contém uma figura e um elemento escrito que pode ser uma palavra ou pseudopalavra. A criança deve circundar os itens corretos e assinalar um X nos itens incorretos. Nesse teste, há sete tipos de itens:

» Tipo 1: corretas regulares (CR), no qual há palavras ortográfica e semanticamente corretas e grafofonemicamente regulares a serem aceitas.

» Tipo 2: corretas irregulares (CI), no qual há palavras ortográfica e semanticamente corretas e grafofonemicamente irregulares a serem aceitas.

» Tipo 3: vizinhas semânticas (VS), no qual há palavras ortograficamente corretas, mas semanticamente incorretas a serem rejeitadas.

» Tipo 4: vizinhas visuais (VV), em que são apresentadas pseudopalavras ortograficamente incorretas, com trocas visuais, a serem rejeitadas.

» Tipo 5: vizinhas fonológicas (VF), no qual aparecem pseudopalavras ortograficamente incorretas, com trocas fonológicas, a serem rejeitadas.

" Tipo 6: pseudopalavras homófonas (PH), no qual são apresentadas pseudopalavras ortograficamente incorretas, embora homófonas a palavras semanticamente corretas, a serem rejeitadas.

» Tipo 7: pseudopalavras estranhas (PE), no qual estarão dispostas pseudopalavras ortograficamente incorretas e fonologicamente e visualmente estranhas a serem rejeitadas. A pontuação total para esse teste é 70 pontos.

Teste Contrastivo de Compreensão Auditiva e de Leitura (TCCAL) (CAPOVILLA; SEABRA, 2013), em que se avalia a habi- 
lidade de compreensão auditiva e de compreensão de leitura silenciosa. É composto por dois subtestes, e cada um possui seis itens de treino e 40 de teste, organizados em ordem crescente de dificuldade:

» Subteste de Compreensão de Sentenças Escritas (SCSE), que tem a finalidade de avaliar a compreensão de leitura. Nele, as frases estão escritas logo acima das figuras e devem ser lidas pela criança avaliada, que tem como tarefa escolher, entre as cinco figuras alternativas, aquela que corresponde à sentença lida.

» Subteste de Compreensão de Sentenças Faladas (SCSF), que mensura a habilidade de compreensão auditiva. O examinador pronuncia as frases em voz alta, visto que não estão escritas no teste. $\mathrm{O}$ avaliado deve escolher, entre as cinco figuras alternativas, aquela que corresponde à sentença ouvida.

A pontuação máxima em cada subteste é de 40 pontos e é interpretada separadamente.

Esses instrumentos foram aplicados nas próprias escolas do estudo mencionado, individualmente ou em grupo. A pesquisa foi realizada durante o período escolar regular em cinco dias diferentes, ao longo de cinco sessões, com duração aproximada de 20 a 30 minutos, no segundo semestre letivo de 2013.

Os resultados dos testes de avaliação de competência em leitura: Provinha Brasil - Leitura, TCLPP e TCCAL - subtestes SCSE e SCSF apresentaram os seguintes resultados de tendência central:

Para a Provinha Brasil - Leitura, as médias e desvio padrão obtidos são descritos na Tabela 5 .

É possível observar na Provinha Brasil - Leitura que as escolas Zona Central e Zona Morros apresentaram médias inferiores entre os sujeitos avaliados em relação às outras duas escolas. Nesse teste, 
TABELA 5 • MÉDIAS E DESVIO PADRÃO NA PROVINHA BRASIL - LEITURA

\begin{tabular}{|c|c|c|c|c|c|c|c|}
\hline \multicolumn{2}{|c|}{ ESCOLA } & \multirow{2}{*}{$\begin{array}{l}\mathbf{N} \\
34\end{array}$} & \multirow{2}{*}{$\begin{array}{c}\text { MÉDIA } \\
16,38\end{array}$} & \multirow{2}{*}{$\begin{array}{c}\text { DESVIO } \\
\text { PADRÃO } \\
2,336\end{array}$} & \multirow{2}{*}{$\begin{array}{c}\text { MÍNIMO } \\
11\end{array}$} & \multirow{2}{*}{$\begin{array}{c}\text { MÁXIMO } \\
20\end{array}$} & \multirow{2}{*}{$\begin{array}{c}\begin{array}{c}\text { PONTUAÇÃO } \\
\text { TOTAL }\end{array} \\
20\end{array}$} \\
\hline $\begin{array}{l}\text { PB - } \\
\text { Leitura }\end{array}$ & $\begin{array}{l}\text { 1- Zona } \\
\text { Leste }\end{array}$ & & & & & & \\
\hline & $\begin{array}{l}\text { 2- Zona } \\
\text { Central }\end{array}$ & 42 & 15,17 & 3,748 & 8 & 20 & 20 \\
\hline & $\begin{array}{l}\text { 3- Zona } \\
\text { Noroeste }\end{array}$ & 32 & 17,34 & 3,543 & 8 & 20 & 20 \\
\hline & $\begin{array}{l}\text { 4- Zona } \\
\text { Morros }\end{array}$ & 34 & 15,18 & 3,148 & 8 & 20 & 20 \\
\hline \multicolumn{2}{|c|}{ Total } & 142 & 15,95 & 3,355 & 8 & 20 & 20 \\
\hline
\end{tabular}

a escola Zona Leste despontou no acerto mínimo de questões. Entretanto, não apresentou a maior média de desempenho.

A média apresentada no desempenho das crianças das escolas denota um nível de leitura em que o aluno lê textos de, aproximadamente, oito a 10 linhas, na ordem direta, de estrutura sintática simples e de vocabulário que pertence ao repertório explorado na escola e tece inferências simples, conforme critério específico de desempenho (BRASIL, 2012d).

No Subteste de Compreensão de Sentença Escrita, a pontuação máxima é de 40 pontos. A escola Zona Leste apresentou pontuação acima da média nos resultados obtidos entre as escolas, enquanto a escola Zona Morros apresentou a menor pontuação média entre as escolas pesquisadas, conforme descrito na Tabela 6 .

Comparando a medida de tendência central (média) da pontuação bruta obtida nos testes PB - Leitura e SCSE aplicados por escola/zoneamento, é possível perceber que há uma variação entre a maior média obtida na PB - Leitura pela escola Zona Noroeste e a maior média obtida no SCSE pela escola Zona Leste.

Nos resultados obtidos no SCSF, a menor média obtida foi apresentada pela escola Zona Central, o que também ocorreu no SCSE, conforme a Tabela 7. 
TABELA 6 • MÉDIA E DESVIO PADRÃO - NO SUBTESTE COMPREENSÃO DE SENTENÇA ESCRITA

\begin{tabular}{|c|c|c|c|c|c|c|c|}
\hline \multicolumn{2}{|c|}{ ESCOLA } & \multirow{2}{*}{$\begin{array}{c}\mathbf{N} \\
34\end{array}$} & \multirow{2}{*}{$\begin{array}{l}\text { MÉDIA } \\
33,56\end{array}$} & \multirow{2}{*}{$\begin{array}{c}\begin{array}{c}\text { DESVIO } \\
\text { PADRÃO }\end{array} \\
8,897\end{array}$} & \multirow{2}{*}{$\begin{array}{c}\text { MÍNIMO } \\
7\end{array}$} & \multirow{2}{*}{$\begin{array}{c}\text { MÁXIMO } \\
40\end{array}$} & \multirow{2}{*}{$\begin{array}{c}\text { PONTUAÇÃO } \\
\text { TOTAL }\end{array}$} \\
\hline SCSE & $\begin{array}{l}\text { 1- Zona } \\
\text { Leste }\end{array}$ & & & & & & \\
\hline & $\begin{array}{l}\text { 2- Zona } \\
\text { Central }\end{array}$ & 42 & 31,88 & 8,980 & 8 & 39 & 40 \\
\hline & $\begin{array}{l}\text { 3- Zona } \\
\text { Noroeste }\end{array}$ & 32 & 29,16 & 13,414 & 0 & 39 & 40 \\
\hline & $\begin{array}{l}\text { 4- Zona } \\
\text { Morros }\end{array}$ & 34 & 27,65 & 11,337 & 6 & 39 & 40 \\
\hline \multicolumn{2}{|c|}{ Total } & 142 & 30,65 & 10,807 & 0 & 40 & 40 \\
\hline
\end{tabular}

FONTE: ELABORADA PELOS AUTORES.

TABELA 7 • MÉDIA E DESVIO PADRÃO NO SUBTESTE DE COMPREENSÃO DE SENTENÇA FALADA

\begin{tabular}{|c|c|c|c|c|c|c|c|}
\hline \multicolumn{2}{|c|}{ ESCOLA } & \multirow{2}{*}{$\begin{array}{c}\mathbf{N} \\
34\end{array}$} & \multirow{2}{*}{$\begin{array}{l}\text { MÉDIA } \\
38,21\end{array}$} & \multirow{2}{*}{$\begin{array}{c}\begin{array}{c}\text { DESVIO } \\
\text { PADRÃOO }\end{array} \\
1,871\end{array}$} & \multirow{2}{*}{$\begin{array}{c}\text { MÍNIMO } \\
32\end{array}$} & \multirow{2}{*}{$\begin{array}{c}\text { MÁXIMO } \\
40\end{array}$} & \multirow{2}{*}{$\begin{array}{c}\text { PONTUAÇÃO } \\
\text { TOTAL }\end{array}$} \\
\hline SCSF & $\begin{array}{l}\text { 1- Zona } \\
\text { Leste }\end{array}$ & & & & & & \\
\hline & $\begin{array}{l}\text { 2- Zona } \\
\text { Central }\end{array}$ & 42 & 36,60 & 3,045 & 26 & 40 & 40 \\
\hline & $\begin{array}{l}\text { 3- Zona } \\
\text { Noroeste }\end{array}$ & 32 & 37,44 & 2,602 & 29 & 40 & 40 \\
\hline & $\begin{array}{l}\text { 4- Zona } \\
\text { Morros }\end{array}$ & 34 & 37,71 & 1,404 & 34 & 40 & 40 \\
\hline \multicolumn{2}{|c|}{ Total } & 142 & 37,44 & 2,416 & 26 & 40 & 40 \\
\hline
\end{tabular}

FONTE: ELABORADA PELOS AUTORES.

No TCLPP, cuja pontuação máxima é 70, os sujeitos da escola Zona Central apresentaram 23 pontos, que é a menor pontuação, e não atingiram o máximo de acertos. A escola Zona Leste apresentou a maior média: 60,12. Nesse teste, a média foi de 56,68 entre os sujeitos avaliados e duas das escolas obtiveram média maior que a obtida pelo total de sujeitos avaliados nas quatro escolas, como pode ser verificado na Tabela 8 . 
TABELA 8 • MÉDIA E DESVIO PADRÃO NO TESTE COMPETÊNCIA EM LEITURA DE PALAVRAS E PSEUDOPALAVRAS

\begin{tabular}{|c|c|c|c|c|c|c|c|}
\hline \multicolumn{2}{|c|}{ ESCOLA } & \multirow{2}{*}{$\begin{array}{c}\mathbf{N} \\
34\end{array}$} & \multirow{2}{*}{$\begin{array}{c}\text { MÉDIA } \\
60,12\end{array}$} & \multirow{2}{*}{$\begin{array}{c}\begin{array}{c}\text { DESVIO } \\
\text { PADRÃO }\end{array} \\
6,494\end{array}$} & \multirow{2}{*}{$\begin{array}{c}\text { MÍNIMO } \\
48\end{array}$} & \multirow{2}{*}{$\begin{array}{c}\text { MÁXIMO } \\
70\end{array}$} & \multirow{2}{*}{$\begin{array}{c}\text { PONTUAÇÃO } \\
\text { TOTAL }\end{array}$} \\
\hline TCLPP & $\begin{array}{l}\text { 1- Zona } \\
\text { Leste }\end{array}$ & & & & & & \\
\hline & $\begin{array}{l}\text { 2- Zona } \\
\text { Central }\end{array}$ & 42 & 53,83 & 9,632 & 23 & 67 & 70 \\
\hline & $\begin{array}{l}\text { 3- Zona } \\
\text { Noroeste }\end{array}$ & 32 & 56,25 & 8,584 & 38 & 70 & 70 \\
\hline & $\begin{array}{l}\text { 4- Zona } \\
\text { Morros }\end{array}$ & 34 & 57,15 & 9,005 & 40 & 70 & 70 \\
\hline \multicolumn{2}{|c|}{ Total } & 142 & 56,68 & 8,797 & 23 & 70 & 70 \\
\hline
\end{tabular}

Após a verificação dos resultados dos testes de avaliação de competência em leitura, foi necessário observar se o zoneamento da escola avaliada exerce algum papel no desempenho dos escolares avaliados. Para tanto, foi utilizado o teste estatístico de análise de variância (Anova). Nesse teste, foi feita a comparação das médias entre os quatro grupos nos testes de avaliação de competência em Leitura (Provinha Brasil - Leitura, SCSE, SCSF, TCLPP), que mostrou que a diferença entre os grupos é significativa para a Provinha Brasil - Leitura (F (3,58); $p=0,01 ; p<0,05)$; SCSE (F $(3,12) ; p=$ $0,02 ; p<0,05)$ e TCLPP (F $(3,42) ; p=0,01 ; p<0,05)$. Na comparação dos grupos em pares, usando a análise post-hoc (Teste de Tukey), os grupos escola Zona Central e escola Zona Noroeste se diferenciaram entre si na Provinha Brasil; os grupos escola Zona Leste e escola Zona Morros não se diferenciaram entre si, e os grupos escola Zona Noroeste e escola Zona Morros também não se diferenciaram entre si em relação ao desempenho no SCSF e TCLPP.

Os grupos escola Zona Leste e escola Zona Central se diferenciaram entre si no Subteste de Compreensão de Sentença Falada (SCSF) e no Teste de Competência de Leitura de Palavras e Pseudopalavras (TCLPP). 
Verificou-se, por meio do teste de correlação de Pearson, que os resultados apresentam correlação positiva e significativa entre os testes de avaliação de competência em leitura. Assim, esse resultado encontra convergência com os estudos de Dias e Seabra (2013) e Seabra e Dias (2012) no que se refere à correlação de $r=0,52$, com $p<0,001$ entre o desempenho no SCSE do TCCAL e o reconhecimento de palavras avaliado pelo TCLPP. Isso também foi observado em relação ao SCSE e a Provinha Brasil - Leitura, com correlações significativas entre o desempenho nesse subteste e escore na Provinha Brasil - Leitura $(r=0,47, \operatorname{com} p<0,001)$. Os subtestes do TCCAL também se correlacionaram entre si $r=0,42, \operatorname{com} p<0,001$.

Para verificar se o efeito dos testes de leitura TCLPP, SCSE, SCSF e de itens de atividades realizados com os pais, assim como de atividades programadas, atividades entre pais e criança, presença de jornais e revistas em casa e tipos de livros em casa, extraídos do Questionário Informativo e Inventário Recursos do Ambiente Familiar - adaptado por Mendes (2014) -, exerce influência nos resultados da Provinha Brasil - Leitura, obtidos em contexto escolar, foi feita a análise de regressão linear, cujo resultado apontou que o $\mathrm{R}=0,655$ indica uma correlação moderada, conforme pesquisa realizada por Mendes (2014).

Essa análise possibilitou a identificação de um modelo que apresenta um coeficiente de determinação 0,429. Isso significa que $42,9 \%$ da variância no desempenho da Provinha Brasil - Leitura é explicado por informações socioambientais, testes de leitura aplicados e preditores de aprendizagem da leitura indicados no Inventário Recursos do Ambiente Familiar. O coeficiente de ajustamento à população foi de 0,339, ou seja, as constantes explicam até 33,9\% da variância na Provinha Brasil - Leitura. No que se refere ao erro padrão de estimativa, pode-se observar que a estimativa de variância é igual a 2,69.

De acordo com os valores de beta, a renda prediz $15 \%$, a compreensão auditiva, $31,1 \%$, e as diferentes escolas avaliadas 
por zoneamento, 6,5\%, no desempenho observado na Provinha Brasil - Leitura. Outro ponto a ser observado diz respeito à renda familiar, que prediz percentual baixo (15\%) no desempenho da Provinha Brasil - Leitura, divergindo dos resultados apontados por Bicalho e Alves (2010).

Assim, seria pertinente avaliar em que medida essa renda é utilizada em benefício da escolarização da criança e do desenvolvimento de práticas educativas que favoreçam a competência em leitura. Por outro lado, é importante ressaltar que 57,7\% das famílias das crianças enquadram-se na renda que varia de um a quatro salários mínimos, e 16,2\% têm renda familiar entre meio e um salário mínimo. Embora a informação sobre a quantidade de integrantes na família não tenha sido obtida, ainda assim aquelas que foram enquadradas entre meio e um salário mínimo apresentam rendas consideradas insuficientes para o mínimo investimento em instrução (IBGE, 2010).

Com relação às descrições das quatro escolas, mesmo estando localizadas em diferentes zonas geográficas, todas enquadram-se no mesmo padrão de infraestrutura física: possuem água, sanitário, energia, esgoto, cozinha, sala de diretoria, sala de professores, biblioteca, laboratório de informática, quadra e/ou local que permite convívio social e desenvolvimento motor, equipamentos de TV, DVD, computadores, impressora, copiadora e acesso à internet (NETO et al., 2013). No entanto, as diferentes escolas descritas no estudo predizem apenas 6,5\% no desempenho observado na Provinha Brasil - Leitura, o que nos leva a questionar em que medida todos esses recursos que a escola apresenta são utilizados em atividades que promovam a competência em leitura.

Os itens que tratam dos recursos do ambiente familiar (atividades realizadas, total de passeios, tipos de livros que pertencem à criança no ambiente familiar) predizem $24,7 \%$ no desempenho observado na Provinha Brasil - Leitura, o que corrobora, 
em parte, os estudos que tratam do suporte do ambiente familiar relacionados à competência em leitura (MARTURANO, 1999; TRIVELLATO-FERREIRA; MARTURANO, 2008; FERREIRA; BARRERA, 2010; SANTOS; GRAMINHA, 2005; ENRICONE; SALLES, 2011; PICCOLO et al., 2012).

Tendo em vista os dados obtidos no estudo de Mendes (2014), é possível observar que o desenvolvimento da competência leitora é pouco influenciado por informações socioambientais e recursos do ambiente familiar que não especifiquem a frequência, a quantidade de diálogos ocorridos entre os pais e as crianças, bem como o vocabulário dos pais.

A partir dos dados socioambientais (renda, escolaridade dos pais), variáveis de leitura (testes de leitura aplicados) e aspectos cognitivos que corroboram a competência em leitura (nomeação automática rápida de letras, números, cores e objetos) e recursos do ambiente familiar obtidos no estudo realizado por Mendes (2014), pode-se identificar tanto os fatores de risco quanto os de proteção, que contribuem para o desenvolvimento educacional, pessoal e social das crianças.

O nível de leitura das crianças do contexto escolar avaliado pelos testes de leitura e Provinha Brasil - Leitura é médio. Neles, é possível estabelecer a relação entre grafemas e fonemas, ler pequenos textos na ordem direta, com estrutura sintática simples, além de localizar informações evidentes em um pequeno texto e tecer inferências simples. Por meio do teste estatístico, foi verificado que não houve diferença nos resultados em relação à idade e ao gênero, e as quatro escolas também não diferiram nos resultados.

Os resultados do desempenho nas provas de leitura apresentaram pequenas nuances em suas médias.

A nomeação automática rápida de letras, números, cores e objetos apresentou correlação negativa significativa com os testes de leitura, o que indica que quanto maior o tempo gasto na nomeação, menor o domínio nas habilidades de leitura. Quanto aos 
dados socioambientais (renda e escolaridade dos pais) e testes de leitura, não houve correlação significativa.

As provas de leitura (Provinha Brasil - Leitura, Compreensão de Sentenças Escritas, Compreensão de Sentenças Faladas e Compreensão de Leitura de Palavras e Pseudopalavras) apresentaram correlação com o suporte do ambiente familiar, preditor da competência de leitura: brinquedos.

$\mathrm{Na}$ análise de regressão, 42,9\% da variância no desempenho na Provinha Brasil - Leitura é explicada pelos dados socioambientais, testes de competência em leitura e recursos do ambiente familiar que podem ser considerados preditores da competência em leitura, sendo o restante possivelmente explicado por características individuais da criança.

Considerando os resultados apresentados, é possível perceber a complexidade que envolve o estudo do desempenho e competência acadêmica e em leitura.

Sugere-se, a partir desses resultados, que o desenvolvimento de habilidades para a compreensão de sentenças escritas, nomeação automática rápida de objetos, letras, números e cores, leitura de palavras e pseudopalavras seja promovido no contexto escolar. Em estudos e experiências futuros, será necessário detalhar ou detectar, em cada aspecto do contexto psicossocioambiental avaliado, a oferta de experiências com linguagem escrita, por meio da leitura compartilhada de histórias, livros, brinquedos didáticos para o desenvolvimento de linguagem etc.

Com relação à competência em leitura e suportes do contexto familiar para o bom desempenho escolar e em leitura, como a participação da família nos processos escolares para estimular um ambiente de aprendizagem profícuo, os resultados, em que pese a divergência em fatores como nível socioeconômico e escolaridade dos pais e a convergência para fatores de suporte familiar, como a presença de brinquedos, livros, passeios realizados com a criança, sugerem a necessidade da implantação de uma 
política pública que valorize a participação familiar na escola com maior contundência do que a existente. Além disso, demandam a implantação de nova modelagem do processo de alfabetização pautada nos pressupostos da abordagem cognitiva e achados da neurociência.

As políticas públicas poderão estar pautadas na valorização da participação familiar no contexto escolar com foco na orientação dos pais em relação às práticas mais bem-sucedidas para ajudar os filhos a desenvolver suas habilidades linguísticas.

Essas práticas deverão envolver a leitura compartilhada de histórias, o estabelecimento de hábitos de diálogos rotineiros entre as crianças e os pais sobre histórias ocorridas no dia a dia, jogos com a utilização de letras e sentenças, jogos de discriminação auditiva, familiarização com livros e outros materiais impressos. Temos como exemplo o que fizeram o governo americano, por meio do Departamento de Educação no programa No child left behind, e o governo da Nova Zelândia, com o programa intitulado Home-school partnerships: literacy programme, quando implementaram políticas públicas de educação que envolviam a participação dos pais no desenvolvimento dessas atividades. 